\title{
LA RELACIÓN ENTRE CONOCIMIENTOS GRAMATICALES Y EL APRENDIZAJE DE PRÁCTICAS DISCURSIVAS: EL ADJETIVO COMO EJEMPLO
}

\section{THE RELATIONSHIP BETWEEN GRAMMATICAL KNOWLEDGE AND DISCOURSE PRACTICE IN LANGUAGE LEARNING: AN ANALYSIS OF THE ADJECTIVE}

\author{
Carmen Rodríguez-Gonzalo \\ Universitat de València \\ crodrig@uv.es \\ Felipe Zayas \\ Grup de Recerca sobre l'Ensenyament i Aprenentatge de Llengües \\ felipezayas@gmail.com
}

Resumen: Una gramática pedagógica ha de recoger los conocimientos gramaticales relevantes para la educación lingüística y ha de mostrar cómo estos conocimientos permiten reflexionar sobre la lengua y utilizarla de forma más consciente en sus distintos usos sociales. En parte, estos conocimientos hacen referencia a las nociones de la tradición gramatical, pero consideradas desde una perspectiva funcional, es decir, en relación con el papel que tienen en el discurso. Por ello, no se trata solo de saber cómo es una forma lingüística, sino también para qué sirve y cómo se utiliza adecuadamente en distintas actividades discursivas. Esta reflexión ha de vincularse, además, a actividades de aprendizaje que muestren la relación de la reflexión gramatical con el dominio de prácticas discursivas. En este trabajo, tomaremos como ejemplo la noción de adjetivo. Examinaremos los conocimientos teóricos disponibles sobre esta noción y exploraremos cómo se usa en la enseńanza de la lengua, fundamentalmente en Educación Secundaria Obligatoria, y para ello tomaremos como referencia algunos de los libros de texto de enseńanza del castellano de mayor circulación en el ámbito estatal. Finalmente, mostraremos algunas vías alternativas de trabajo gramatical en el aula, relacionadas con el aprendizaje del uso.

Palabras clave: gramática pedagógica, adjetivo, uso reflexivo de la lengua, reflexión metalingüística. 
Carmen Rodríguez-Gonzalo \& Felipe Zayas

La relación entre conocimientos gramaticales y el aprendizaje

de prácticas discursivas: el adjetivo como ejemplo

\begin{abstract}
A pedagogical grammar needs to include the relevant grammatical knowledge for linguistic education, and it needs to show how this knowledge allow us to reflect upon the language being learned and use it more consciously in different social uses. In part, this knowledge refers to the traditional grammatical notions, but from a functional perspective; that is, in relation to the role they play in discourse. However, a pedagogical grammar is not only about linguistic forms, but also about what they are for and how they are used appropriately in discursive activities. In addition, language forms and use must also be related to learning activities that show the links between grammatical reflection and the mastering of discursive practices. In this article, we take as an example the notion of adjective, and we examine the theoretical knowledge available about this notion and explore how it is used in language teaching, mainly in secondary education. In order to do this, we take as a reference some of the most regularly used textbooks for the teaching of Spanish in Spain. Finally, we show some alternative ways to carry out grammatical work in the classroom with links to the learning of adjective use.
\end{abstract}

Key words: pedagogical grammar, adjective, reflexive use of language, metalinguistic awareness.

\title{
es es es
}

\section{INTRODUCCIÓN}

En este trabajo partimos de una posición ampliamente defendida sobre la enseñanza de la gramática en la educación no universitaria: la necesidad de que esté vinculada con el aprendizaje de los usos de la lengua, especialmente con la escritura, más allá de los ineludibles requerimientos normativos. Para ello, la enseñanza de la gramática ha de estar basada en la reflexión metalingüística (Zayas \& Rodríguez I992; Zayas 2004 y 20II; Rodríguez Gonzalo 20II y 20I2a).

Desde esta posición, consideramos necesaria una gramática pedagógica que recoja los conocimientos gramaticales relevantes para la educación lingüística de los estudiantes y que muestre, además, cómo la reflexión sobre estos conocimientos contribuye a que los hablantes sean capaces de adecuar su uso a las diversas esferas de la actividad social. Es decir, entendemos que una gramática pedagógica ha de considerar no solo los contenidos lingüísticos pertinentes sino los criterios para su enseñanza y su aprendizaje, en línea con los planteamientos de Camps (2017) o de Camps \& Milian en este mismo monográfico.

Los contenidos de una gramática pedagógica, desde nuestra perspectiva, hacen referencia a nociones básicas de la enseñanza gramatical (clases de palabras, estructuras sintácticas simples y complejas) o a relaciones entre elementos lingüísticos en unidades 
supraoracionales como el párrafo o el texto. Estos contenidos habrán de presentarse y llevarse al aula vinculando las formas lingüísticas con el papel que tienen en el discurso. No se trata solo de saber cómo es una forma lingüística, sino sobre todo para qué la utilizamos y en qué prácticas discursivas, entendidas como usos sociales, lo hacemos. Y puesto que hablamos de enseñanza-aprendizaje, este tipo de reflexión ha de integrarse en secuencias didácticas en las que el aprendizaje sea posible y tenga sentido. Por ello abogamos por espacios didácticos como las secuencias didácticas de gramática (Camps 2003a; Camps \& Zayas 2006; Milian \& Ribas 2017), ya sea para vincular la reflexión gramatical con tareas de escritura (Zayas 1993, Rodríguez, Martínez \& Zayas 1995, Ribas \& Verdaguer 2006), ya sea como proyectos de investigación sobre distintos aspectos gramaticales (Gutiérrez 1999; Camps \& Fontich 2003; Guasch, Gràcia \& Carrasco 2004; Fontich 2006; Rodríguez Gonzalo 20I2b). ${ }^{1}$

En definitiva, consideramos que la elaboración de una gramática pedagógica exige, por una parte, redefinir los conocimientos gramaticales desde una perspectiva discursiva y, por otra, mostrar cómo se pueden construir estos conocimientos en la clase de lengua y qué papel desempeñan en el aprendizaje de las prácticas discursivas. En este trabajo, referido básicamente al castellano como lengua primera de los estudiantes, pretendemos avanzar en este sentido. Para ello hemos elegido como ejemplo la noción de adjetivo, presente en todos los currículos de lenguas, tanto en Primaria como en Educación Secundaria Obligatoria (ESO).

En los apartados que siguen, sintetizaremos en primer lugar los conocimientos teóricos disponibles sobre esta noción en la Nueva gramática básica de la lengua española (NGBLE, 20II), obra divulgativa y rigurosa, pensada para el conjunto de hispanohablantes. A continuación, revisaremos el tratamiento dado al adjetivo en los libros de texto de enseñanza del castellano en la ESO en dos de los proyectos editoriales de mayor circulación en el ámbito estatal, ambos del 2007. Consideramos que, dada la implantación de estas editoriales en el panorama educativo español, este análisis nos acerca a la manera más extendida de trabajar la gramática en las aulas en estos momentos. Tomando en consideración este doble análisis, mostraremos algunas vías alternativas de trabajo en el aula, como ejemplo de los vínculos didácticos entre la reflexión sobre la lengua y el aprendizaje de prácticas discursivas y mostraremos asimismo algunos criterios para abordar la progresión de la noción durante la escolaridad. Todo ello nos servirá para fundamentar nuestras conclusiones sobre las vías hacia una gramática pedagógica que rompa la rígida separación tradicional entre uso lingüístico y reflexión sobre la lengua.

I. De las secuencias didácticas de gramática, por cuestiones de espacio, no nos ocuparemos en este trabajo. Remitimos, pues, a las referencias citadas.

Caplletra 63 (Tardor, 2017), pp. 245-277 
Carmen Rodríguez-Gonzalo \& Felipe Zayas

La relación entre conocimientos gramaticales y el aprendizaje

de prácticas discursivas: el adjetivo como ejemplo

\section{EL ADJETIVO EN LA NUEVA GRAMÁTICA BÁSICA DE LA LENGUA ESPANOLA (NGBLE)}

La NGBLE es un manual de divulgación sobre la lengua, no una gramática pensada con fines didácticos. En ella se mantiene la "esencia doctrinal y terminológica de la Nueva gramática y del Manual, y se conservan asimismo su rigor conceptual, su coherencia explicativa y su vocación normativa» (2OII: XVII-XVIII). Reúne un conjunto de conocimientos sobre la lengua considerados básicos y accesibles para todos aquellos hispanohablantes que han recibido una primera instrucción (estudios de primaria y secundaria). Por ello, aunque no se trata de una gramática escolar, su carácter divulgativo nos permite tomarla como referencia para nuestro propósito.

En una enseńanza de la gramática vinculada al uso, es necesario que la descripción gramatical no sea únicamente de tipo formal sino que ponga en relación las formas lingüísticas con los significados y las intenciones. Así pues, en este apartado haremos un recorrido por la descripción gramatical relacionada con el adjetivo, atentos a aquellos aspectos que pudieran facilitar más claramente la integración de la reflexión gramatical con el uso de la lengua.

Como clase de palabra, el adjetivo se define en la $N G B L E$ a partir de tres criterios: a) morfológico: palabra variable con flexión de género y número para mostrar la concordancia con el nombre; y palabra que se puede formar mediante afijos (morfología léxica o derivativa); b) sintáctico: núcleo de los grupos adjetivales, que funcionan como modificadores del sustantivo o como atributos; y c) semántico: el adjetivo aporta un contenido que se predica de un nombre o de un grupo nominal y que denota cualidades, propiedades, tipos, relaciones, cantidades, etc.

\section{I EL ADJETIVO DESDE UNA PERSPECTIVA MORFOLÓGICA}

La descripción del adjetivo centrada en la morfología flexiva no tiene una conexión clara con la reflexión enfocada hacia el uso, excepto en lo que se refiere a cuestiones de normativa, aunque es un conocimiento que forma parte de la cultura gramatical básica y que resulta útil, por ejemplo, en el manejo de diccionarios. Más interés tiene la descripción del adjetivo desde el punto de vista de la morfología léxica o derivativa. Importa aquí examinar los adjetivos formados a partir de nombres (aduanero), de verbos (sorprendente) y de adjetivos (grandioso).

En esta descripción se concede una gran importancia al significado que aportan los sufijos, presentados en dos grandes grupos: los que forman adjetivos calificativos 
y los que forman adjetivos relacionales. Los adjetivos calificativos denotan cualidades o propiedades que se agregan al significado del sustantivo: día caluroso, deportista ejemplar. De forma diferente, los adjetivos relacionales aportan rasgos que permiten clasificar las entidades: presidente honorario, llamada telefónica (un tipo de presidente, de llamada). La NGBLE ilustra esta diferencia semántica con dos ejemplos: perro ladradorlperro labrador, gato sibilinol gato siamés.

Son sufijos característicos de los adjetivos relacionales -al, -ar y -ero (muscular, ministerial, pesquero). En cambio, -oso (musculoso) es más común entre los calificativos. Además, los adjetivos relacionales no admiten sufijos que solo pueden aparecer en adjetivos calificativos, como los de grado (bellísimo, celebérrimo) y los apreciativos (nuevecita, simpaticón).

En el apartado dedicado a la prefijación, se concede un amplio espacio a la clasificación de los prefijos según el significado (locativos, temporales y aspectuales, cuantificativos, gradativos y escalares, etc.). Aunque de estas clases de prefijos solo algunas afectan a las bases adjetivas: reincidente (aspectual), plurianual (cuantificativo), superfino (gradativo), desleal (negativo), interplanetario (de incidencia argumental). Tienen interés las características fonológicas y morfológicas con repercusiones en la normativa ortográfica, como en irresponsable o imbatible.

En cuanto a la composición, la $N G B L E$ distingue los siguientes tipos de composición adjetival: $a$ ) nombre y adjetivo ( $\mathrm{N}-i-\mathrm{A})$, boquiabierto, cuellilargo; $\mathrm{N}+\mathrm{A}$ : vasodilatador, $b)$ doble adjetivo $(\mathrm{A}+\mathrm{A})$ : verdinegro, teórico-práctico. Es evidente que los dos tipos de compuestos de nombre y adjetivo tienen funciones comunicativas muy diferentes: en el primero encontramos adjetivos calificativos con función valorativa; en el segundo, adjetivos relacionales con función clasificadora.

Como hemos examinado, algunos mecanismos de la morfología derivativa implican problemas de uso que se sitúan en el ámbito de la normativa; pero la $N G B L E$, al resaltar la dimensión semántica de estos mecanismos, proporciona vías para la reflexión sobre los usos de los adjetivos derivados y compuestos tanto en la comprensión como en la composición de textos.

\subsection{EL ADJETIVO DESDE UNA PERSPECTIVA SEMÁNTICA}

Como hemos visto en 2.I, la $N G B L E$ establece una importante distinción entre adjetivos relacionales y calificativos. Se trata de una distinción de base semántica, pero también hay entre ellos diferencias morfológicas y sintácticas. Ya se ha señalado alguna diferencia morfológica, como la preferencia por unos tipos de sufijos. Interesará ahora detenerse en algunas diferencias en el comportamiento sintáctico. 
Carmen Rodríguez-Gonzalo \& Felipe Zayas

La relación entre conocimientos gramaticales y el aprendizaje

de prácticas discursivas: el adjetivo como ejemplo

Los adjetivos relacionales establecen una unidad semántica con el sustantivo al que modifican, lo que explica el comportamiento sintáctico singular de estos adjetivos: no pueden anteponerse al sustantivo (*una periodística crónica), no pueden ir separados del nombre por un adjetivo calificativo (*un submarino nuevo nuclear) y no pueden ser atributos.

También se distinguen estas dos clases de adjetivos por su diferente nivel jerárquico cuando coinciden en el mismo grupo nominal. Así, en una fabulosa nave espacial o una nave espacial fabulosa, el adjetivo relacional forma bloque con el sustantivo (nave espacial) y el adjetivo calificativo lo modifica (fabulosa). Finalmente, la distinta naturaleza semántica de una y otra clase de adjetivo impide su coordinación: * tormenta tropical y fuerte.

Además de esta distinción, en la NGBLE se describen diferentes usos de los adjetivos calificativos: epítetos, usos especificativos y usos explicativos. Todos tienen marcados efectos semánticos que implican también comportamientos sintácticos característicos, como la posición o su alternancia con otras construcciones.

\subsection{EL ADJETIVO DESDE UNA PERSPECTIVA SINTÁCTICA}

Desde una perspectiva sintáctica se presenta el adjetivo como núcleo del grupo adjetival, con dos funciones posibles: modificador del sustantivo y atributo. En el primer caso, el grupo adjetival es definido en la $N G B L E$ como «una construcción sintáctica cuyo núcleo es un adjetivo que puede recibir modificadores y complementos» (I85). Los modificadores son adverbios, generalmente de grado (poco, muy, más...), pero también de otros tipos, como de punto de vista (países lingüisticamente heterogéneos) o de modalidad (escena lamentablemente cotidiana). Los complementos son grupos preposicionales, y pueden ser de dos tipos: complementos argumentales y adjuntos. Los complementos argumentales están exigidos por el significado del adjetivo: digno de lástima, amante de la música), a diferencia de los complementos adjuntos: lleno hasta la mitad.

El grupo adjetival incide en el núcleo del grupo nominal dentro de una estructura en la que los elementos están jerarquizados. ${ }^{2}$ En ella, el adjetivo calificativo puede modificar a un sustantivo, pero también a un grupo nominal formado por un

2. En la $N G B L E$ (2OII: 242) se señala la equivalencia semántica entre las relativas y los adjetivos en su relación con el sustantivo al que modifican. En este trabajo solo nos detenemos en las estructuras en las que el adjetivo tiene una presencia explícita. 
sustantivo y un complemento de interpretación clasificativa. Así, en tres hermosos libros de poemas, el adjetivo hermosos modifica a libros de poemas, ya que este grupo nominal forma una unidad semántica, igual que en el ejemplo comentado antes (una fabulosa nave espacial / una nave espacial fabulosa). En definitiva, el complemento de interpretación clasificativa y el de interpretación calificativa o valorativa se sitúan en diferente nivel jerárquico.

Como ocurre dentro del grupo nominal, los componentes del grupo adjetival se relacionan entre sí de forma jerarquizada. Así, en demasiado cansado de esperar, el núcleo cansado y su complemento de esperar forman un primer segmento al que se subordina el modificador demasiado. Finalmente, habría que seńalar que el adjetivo puede ser núcleo de construcciones comparativas (Este tejido es tan suave como aquel) y consecutivas (Se sentian tan felices que no se daban cuenta de nada), de las que no nos ocuparemos en el marco de este trabajo.

En el segundo caso, el adjetivo puede desempeñar la función de atributo, junto con otras categorías gramaticales. Los atributos adjetivales son los más característicos, ya que aparecen en todas las modalidades de la atribución: $a$ ) con los verbos copulativos ser, estar y parecer; b) con verbos semicopulativos (Los contratantes quedaron satisfechos) y c) con verbos plenos (complementos predicativos), como en Los bueyes caminaban lentos.

Las oraciones con verbo copulativo se construyen con ser o con estar según su significado. Se señalan también adjetivos que cambian de significado según se construyan con uno u otro verbo (ser listolestar listo; ser ricolestar rico) y se indican otros factores sintácticos y semánticos que intervienen en la aparición de ser o de estar. En las oraciones con verbos semicopulativos, los atributos adjetivales aparecen con verbos de cambio (hacerse, volverse, etc.), de permanencia, persistencia o continuidad (andar, continuar, etc.), de manifestación o presencia de estados o propiedades (encontrarse, mostrarse, etc.). Finalmente, se distingue entre adjetivos que son complementos predicativos del sujeto (caminaba exhausta) o del complemento directo (lo compraste caro).

En conclusión, el análisis realizado muestra la importancia que la $N G B L E$ concede a la dimensión semántica, lo que aproxima esta nueva gramática a los enfoques funcionales y cognitivos. Algunos ejemplos de esta perspectiva son: la importancia que se da al significado de los derivados, la distinción entre adjetivos calificativos y relacionales o la distinción — dentro del grupo adjetival — entre complementos argumentales y adjuntos, basada en el significado del adjetivo. Además, las características semánticas de las formas lingüísticas examinadas se ponen en relación con su comportamiento morfológico y sintáctico. El ejemplo más claro es la descripción de las diferencias semánticas, morfológicas y sintácticas entre adjetivos calificativos y 
Carmen Rodríguez-Gonzalo \& Felipe Zayas

La relación entre conocimientos gramaticales y el aprendizaje

de prácticas discursivas: el adjetivo como ejemplo

adjetivos relacionales. Esta atención a las relaciones entre semántica y morfosintaxis permite descripciones más precisas que pueden ayudar a la reflexión en el aula. La distinción entre adjetivos relacionales y calificativos ofrece posibilidades de trabajo en el aula mucho más ricas que la tradicional entre adjetivos determinativos y calificativos, tanto en actividades de comprensión lectora como de composición de textos.

\section{EL ADJETIVO COMO CONTENIDO GRAMATICAL EN LOS LIBROS DE TEXTO}

En este apartado presentamos la visión de los contenidos escolares sobre el adjetivo tal y como aparecen fijados en los libros de texto previos a la última modificación legislativa (LOMCE 2013). Para ello hemos seleccionado ocho manuales de lengua castellana, de $\mathrm{I}^{\mathrm{o}}$ a $4^{\mathrm{o}}$ de ESO, ${ }^{3}$ pertenecientes a dos de los proyectos editoriales de mayor implantación en la enseñanza en España (edición de 2007, con la anterior ley orgánica, LOE, en vigor): Santillana-Proyecto La casa del saber y SM-Enlace.

En ambos casos, la organización de los contenidos en cada unidad se realiza en bloques (cuadros I y 2), como viene siendo habitual en la mayor parte de los libros de texto de los últimos años (Zayas \& Rodríguez 2003; Ferrer \& Rodríguez 2010).

Cuadro I. Organización del libro de $\mathrm{I}^{\mathrm{o}}$ de ESO. Santillana-La casa del saber

\begin{tabular}{|l|l|l|l|l|l|l|}
\hline \multirow{4}{*}{$\begin{array}{c}\text { SANTILLANA- } \\
\text { La casa del saber }\end{array}$} & \multicolumn{3}{|c|}{ COMUNICACIÓN (unidades 1-6) } & \multicolumn{2}{|c|}{ ESTUDIO DE LA LENGUA } \\
\cline { 2 - 3 } & Leer & Aprender & Leer & Escribir & & \multirow{2}{*}{ LITERATURA (unidades 7-12) } \\
\cline { 2 - 4 } & Leer & $\begin{array}{l}\text { Formas y } \\
\text { géneros }\end{array}$ & Leer & Escribir & Vocabulario & Ortografía \\
\hline
\end{tabular}

Cuadro 2. Organización del libro de I $^{\mathrm{o}}$ de ESO. SM-Enlace

\begin{tabular}{|l|l|l|l|l|l|l|l|}
\hline \multirow{3}{*}{ SM-Enlace } & \multirow{3}{*}{ TEXTOS } & \multirow{2}{*}{ ESCRIBIR } & \multicolumn{2}{|c|}{$\begin{array}{c}\text { CONOCIMIENTO } \\
\text { DE LA LENGUA }\end{array}$} & \multicolumn{2}{|c|}{$\begin{array}{c}\text { USO } \\
\text { DE LA }\end{array}$} & \multicolumn{2}{|c|}{ LITERATURA } \\
& & Gramática & Ortografía & LENGUA & $\begin{array}{l}\text { Estudio de } \\
\text { la literatura }\end{array}$ & $\begin{array}{l}\text { Texto y } \\
\text { actividades }\end{array}$ \\
\hline
\end{tabular}

3. Incluimos la relación del material analizado en el Anexo. 
Así, en cada unidad se agrupan contenidos de distintos bloques, cada uno con su propia lógica organizativa, lo que se traduce en una escasa o nula coordinación entre los distintos aspectos del aprendizaje lingüístico-literario. Las unidades didácticas se convierten en misceláneas de aspectos diversos. Por ejemplo, al seleccionar las unidades en las que aparece explícitamente el contenido de nuestro análisis, el adjetivo, encontramos lo siguiente:

Cuadro 3. Organización de las unidades io y II ( ${ }^{\circ}$ ESO). Santillana-La casa del saber

\begin{tabular}{|c|c|c|c|c|c|c|c|}
\hline \multirow{2}{*}{$\begin{array}{l}\text { SANTILLANA- } \\
\text { Lacasadelsaber }\end{array}$} & \multicolumn{4}{|c|}{ LITERATURA } & \multicolumn{3}{|c|}{ ESTUDIO DE LA LENGUA } \\
\hline & Leer & $\begin{array}{l}\text { Formas y } \\
\text { géneros }\end{array}$ & Leer & Escribir & Gramática & Vocabulario & Ortografía \\
\hline $\begin{array}{l}\text { I }^{\circ} \text { ESO } \\
\text { Unidad Io } \\
\text { La poesía popular } \\
\text { El adjetivo } \\
\text { calificativo }\end{array}$ & $\begin{array}{l}\text { - Romance } \\
\text { del conde } \\
\text { Olmos } \\
\text { - Ya no me } \\
\text { pondré la } \\
\text { guirnalda } \\
\text { - iAy que } \\
\text { no puedo } \\
\text { segar! } \\
\text { - El señor } \\
\text { don Gato }\end{array}$ & $\begin{array}{l}\text { La poesía } \\
\text { popular }\end{array}$ & $\begin{array}{l}\text { - Las señas } \\
\text { del esposo } \\
\text { - El lunes } \\
\text { pasé } \\
\text { contento... } \\
\text { - ¿Por qué } \\
\text { me besó } \\
\text { Perico? }\end{array}$ & $\begin{array}{l}\text { Un } \\
\text { juego } \\
\text { infantil }\end{array}$ & $\begin{array}{l}\text { El adjetivo } \\
\text { calificativo }\end{array}$ & La salud & $\begin{array}{l}\text { Pausa } \\
\text { interna: } \\
\text { la coma }\end{array}$ \\
\hline $\begin{array}{l}\mathrm{I}^{\circ} \text { ESO } \\
\text { Unidad II } \\
\text { Las narraciones } \\
\text { populares } \\
\text { Los adjetivos } \\
\text { determinativos }\end{array}$ & $\begin{array}{l}\text { - La calle } \\
\text { de la } \\
\text { Cabeza } \\
\text { - Respetar } \\
\text { el silencio } \\
\text { - Cipariso }\end{array}$ & $\begin{array}{l}\text { Las } \\
\text { narraciones } \\
\text { populares }\end{array}$ & $\begin{array}{l}\text { - El anillo } \\
\text { encantado }\end{array}$ & $\begin{array}{l}\text { Una } \\
\text { leyenda } \\
\text { de terror }\end{array}$ & $\begin{array}{l}\text { Los adjetivos } \\
\text { determinativos }\end{array}$ & La memoria & $\begin{array}{l}\text { Pausa } \\
\text { interna: } \\
\text { los dos } \\
\text { puntos }\end{array}$ \\
\hline
\end{tabular}

Cuadro 4. Organización de la unidad 6 ( ${ }^{\circ}$ ESO). SM-Enlace

\begin{tabular}{|c|c|c|c|c|c|c|c|}
\hline \multirow{2}{*}{ SM-Enlace } & \multirow{2}{*}{ TEXTOS } & \multirow{2}{*}{ ESCRIBIR } & \multicolumn{2}{|c|}{$\begin{array}{c}\text { CONOCIMIENTO } \\
\text { DE LA LENGUA }\end{array}$} & \multirow{2}{*}{$\begin{array}{c}\text { USO } \\
\text { DE LA } \\
\text { LENGUA }\end{array}$} & \multicolumn{2}{|c|}{ LITERATURA } \\
\hline & & & Gramática & Ortografía & & $\begin{array}{l}\text { Estudio de } \\
\text { la literatura }\end{array}$ & $\begin{array}{l}\text { Texto y } \\
\text { actividades }\end{array}$ \\
\hline $\begin{array}{l}\text { I }^{\mathrm{O}} \text { ESO- Unidad } 6 \\
\text { UN MUNDO } \\
\text { POR } \\
\text { DESCUBRIR } \\
\text { [Michael Ende: } \\
\text { La historia } \\
\text { interminable] }\end{array}$ & $\begin{array}{l}\text { Los textos } \\
\text { narrativos }\end{array}$ & $\begin{array}{l}\text { Una } \\
\text { solicitud }\end{array}$ & $\begin{array}{l}\text { El } \\
\text { adjetivo }\end{array}$ & $\begin{array}{l}\text { Uso de } \\
b, v\end{array}$ & $\begin{array}{l}\text { Mostrar } \\
\text { cortesía }\end{array}$ & $\begin{array}{l}\text { El género } \\
\text { narrativo. } \\
\text { El cuento }\end{array}$ & $\begin{array}{l}\text { Las tres } \\
\text { rejas } \\
\text { [Anónimo] }\end{array}$ \\
\hline
\end{tabular}


Carmen Rodríguez-Gonzalo \& Felipe Zayas

La relación entre conocimientos gramaticales y el aprendizaje

de prácticas discursivas: el adjetivo como ejemplo

Teniendo en cuenta este tipo de organización, que en sí mismo constituye una primera dificultad para un aprendizaje que relacione contenidos gramaticales y uso lingüístico, en nuestro análisis del tratamiento del adjetivo abordamos su presencia explícita como contenido en cada proyecto editorial, en el bloque denominado en ambos casos "Gramática», así como su presencia, implícita o explícita, en los bloques dedicados al estudio de los textos, literarios o no, desde la perspectiva de la comprensión o de la producción. Este rastreo nos permitirá establecer conclusiones sobre las conexiones entre el tratamiento gramatical de la noción y el planteamiento sobre su uso (desde el análisis o desde la producción) en cada proyecto editorial.

\section{I EL ADJETIVO COMO CONTENIDO GRAMATICAL EXPLÍCITO EN LOS MANUALES} DE ESO

Para analizar el tratamiento dado al adjetivo como contenido gramatical explícito nos hemos detenido en los siguientes aspectos: definición, tipos, características, uso y actividades de aprendizaje planteadas. Mediante los tres primeros (definición, tipos, características) nos aproximamos a lo que Barth (2004: \$r.4.I), hablando del aprendizaje de la abstracción, denomina la estructura operatoria de los conceptos, y mediante los dos segundos (uso y actividades de aprendizaje), nos detenemos en dos aspectos necesarios para determinar el planteamiento didáctico que se realiza.

El punto de partida son los manuales de primero de ESO. En los dos casos analizados, los contenidos gramaticales consideran las clases de palabras y el adjetivo entre ellas. En el proyecto Santillana-La casa del saber, son dos las unidades dedicadas a los adjetivos, porque se parte de la consideración como tales tanto de los calificativos como de los determinativos. Al principio de cada unidad, se explicitan los objetivos de aprendizaje para el alumno ("qué vas a aprender»). En el caso de los adjetivos calificativos (unidad IO: I43): qué son los adjetivos calificativos y cómo se clasifican; qué son los grados del adjetivo y cómo se expresan. En el caso de los adjetivos determinativos (unidad II: 157): qué es un adjetivo determinativo; qué clases de adjetivos determinativos hay y qué formas presentan. La síntesis de contenidos y actividades propuestos se recoge en el cuadro 5 . 
Carmen Rodríguez-Gonzalo \& Felipe Zayas

La relación entre conocimientos gramaticales y el aprendizaje de prácticas discursivas: el adjetivo como ejemplo

Cuadro 5. El adjetivo como contenido gramatical explícito en $\mathrm{I}^{\circ} \mathrm{ESO}$ (proyecto Santillana-La casa del saber)

\begin{tabular}{|c|c|c|c|c|c|}
\hline Adjetivo & Definición & Tipos/Clases & Características & Uso & Actividades de aprendizaje \\
\hline $\begin{array}{l}\text { Proyecto } \\
\text { Santillana- } \\
\text { La casa del } \\
\text { saber } \\
\text { Io ESO } \\
\text { Unidad Io- } \\
\text { Gramática } \\
\text { (pp. I50- } \\
\text { I52) } \\
\text { Unidad II- } \\
\text { Gramática } \\
\text { (pp. I64- } \\
\text { I66 }\end{array}$ & $\begin{array}{l}\text { «Son palabras } \\
\text { variables que } \\
\text { acompañan } \\
\text { o se refieren } \\
\text { a un } \\
\text { sustantivo } \\
\text { destacando } \\
\text { una cualidad } \\
\text { o una } \\
\text { propiedad } \\
\text { suya o } \\
\text { limitando su } \\
\text { extensión» } \\
\text { (unidad IO, } \\
\text { p. I5o). }\end{array}$ & $\begin{array}{l}\frac{\text { Calificativos }}{\text { (funcionan }} \\
\text { como } \\
\text { complementos } \\
\text { del sustantivo). } \\
\text { Determinativos } \\
\text { Pueden } \\
\text { funcionar } \\
\text { como } \\
\text { determinantes } \\
\text { (su coche) } \\
\text { o como } \\
\text { complementos } \\
\text { (el coche suyo) } \\
\text { (unidad io, } \\
\text { p. I5o). } \\
\text { Determinativos: } \\
\text { posesivos, } \\
\text { demostrativos, } \\
\text { indefinidos, } \\
\text { numerales, } \\
\text { interrogativos } \\
\text { y exclamativos } \\
\text { (unidad II, } \\
\text { p. I64). }\end{array}$ & $\begin{array}{l}\text { Calificativos: } \\
\text { - Forma } \\
\text { una o dos } \\
\text { terminaciones; } \\
\text { - Posición: } \\
\text { adjetivos } \\
\text { explicativos, } \\
\text { Llegué un soleado } \\
\text { día de verano; } \\
\text { especificativos, } \\
\text { Ayer fue un } \\
\text { día soleado, y } \\
\text { con cambio de } \\
\text { significado según } \\
\text { posición, Un } \\
\text { pobre hombre. } \\
\text { Un hombre pobre. } \\
\text { - Grados: positivo, } \\
\text { comparativo, } \\
\text { superlativo } \\
\text { (unidad Io, } \\
\text { pp. I5I-I52). } \\
\text { Determinativos: } \\
\text { en cada tipo } \\
\text { - contenido que } \\
\text { expresa } \\
\text { - forma } \\
\text { (paradigmas) }\end{array}$ & $\begin{array}{l}\text { No hay } \\
\text { indica- } \\
\text { ciones } \\
\text { sobre este } \\
\text { aspecto. }\end{array}$ & $\begin{array}{l}\text { Sobre calificativos: } \\
\text { - Introducir adjetivos junto } \\
\text { a sustantivos dados, en } \\
\text { oraciones simples y en un } \\
\text { párrafo de inicio de una } \\
\text { narración. } \\
\text { - Diferenciar adjetivos } \\
\text { explicativos y especificativos } \\
\text { en oraciones dadas. } \\
\text { - Reescribir oraciones } \\
\text { cambiando el adjetivo de } \\
\text { posición y explicando el } \\
\text { cambio. } \\
\text { - Añadir adjetivos a } \\
\text { sustantivos en grupos } \\
\text { nominales con } y \text {, para } \\
\text { observar la concordancia de } \\
\text { número. } \\
\text { - Identificar los adjetivos y el } \\
\text { grado en que están en frases } \\
\text { dadas. } \\
\text { - Describir al protagonista } \\
\text { de una película empleando } \\
\text { adjetivos dados en el grado } \\
\text { que se indican. } \\
\text { Sobre determinativos: } \\
\text { - Identificar distintos tipos de } \\
\text { adjetivos determinativos en } \\
\text { oraciones dadas. } \\
\text { - Rellenar huecos con } \\
\text { adjetivos determinativos y } \\
\text { justificar la elección. } \\
\text { - Otras actividades: piensa y } \\
\text { responde (ipuede haber un } \\
\text { posesivo y un demostrativo en } \\
\text { el mismo sintagma nominal?, } \\
\text { p. I65; escribir preguntas con } \\
\text { intetrogativos para respuesta } \\
\text { dadas, p. I66). }\end{array}$ \\
\hline
\end{tabular}

Por lo que respecta a la progresión de la noción, el planteamiento de primer curso, sustentado en el significado y la forma, se amplía en $2^{\circ}$ de ESO con la noción de función, ya que los contenidos gramaticales en este curso se centran en la sintaxis, 
Carmen Rodríguez-Gonzalo \& Felipe Zayas

La relación entre conocimientos gramaticales y el aprendizaje

de prácticas discursivas: el adjetivo como ejemplo

especialmente de la oración simple. Se completan así los tres ejes en los que se apoya la noción: forma, significado y función (cuadro 6). La forma y el significado (planteamiento morfológico) sirven para introducir la noción en $\mathrm{I}^{\mathrm{o}}$, tras lo cual se añade el planteamiento sintáctico, que incorpora la función, en $2^{\circ}$ de ESO. El manual de $3^{\circ}$ retoma la noción incorporando los tres ejes a la vez (planteamiento morfosintáctico) e introduciendo las proposiciones adjetivas como tipo de oración compuesta. En $4^{\mathrm{o}}$, por último, el planteamiento forma-significado-función se centra básicamente en las proposiciones adjetivas. Tanto en $3^{\circ}$ como en $4^{\mathrm{o}}$ se añaden algunas observaciones normativas en relación con el uso correcto del adjetivo.

En síntesis, en todo el proyecto se parte del adjetivo como noción común a dos grandes tipos: determinativos y calificativos, aunque cuando el término adjetivo se usa sin delimitar, por defecto se alude a los calificativos. Se incide en el carácter variable de la palabra, concretándolo en la concordancia de género y número y en los grados, en el caso de los calificativos, pero no se alude a la formación, ni a los cambios de categoría de la palabra. ${ }^{4}$ Solo se habla del uso para aludir a algunas cuestiones de norma culta, entendidas como usos correctos o incorrectos (escritura de ordinales, por ejemplo).

Las actividades de aprendizaje se centran básicamente en la identificación y manipulación de las características morfológicas y sintácticas del adjetivo, bien en el marco de la palabra o de la oración, con algún uso excepcional del párrafo. Nunca se habla del valor comunicativo del adjetivo ni de su uso en textos o actividades discursivas.

Cuadro 6. Progreso de la noción de adjetivo como contenido gramatical explícito en los manuales de $\mathrm{I}^{\mathrm{o}}$ a $4^{\circ}$ ESO (proyecto Santillana-La casa del saber)

\begin{tabular}{|c|c|c|c|}
\hline$I^{\circ}$ ESO & $2^{\circ}$ ESO & $3^{\circ} \mathrm{ESO}$ & $4^{\circ} \mathrm{ESO}$ \\
\hline $\begin{array}{l}\text { Adjetivos } \\
\text { determinativos y } \\
\text { calificativos. }\end{array}$ & Adjetivos calificativos. & $\begin{array}{l}\text { Adjetivos } \\
\text { determinativos y } \\
\text { calificativos. }\end{array}$ & Proposiciones adjetivas. \\
\hline Forma y significado. & Función. & $\begin{array}{l}\text { Forma, significado y } \\
\text { función. } \\
\text { Proposiciones adjetivas. } \\
\text { Uso: norma culta. }\end{array}$ & $\begin{array}{l}\text { Forma, significado y } \\
\text { función. } \\
\text { Uso: norma culta. }\end{array}$ \\
\hline
\end{tabular}

4. Como una característica morfológica, se alude a que los adjetivos pueden combinarse con la forma neutra del artículo (lo), en ejemplos como lo bueno, lo extraño (Santillana-La casa delsaber, $\mathrm{I}^{\circ} \mathrm{ESO}$, unidad IO: I5O). 
En el proyecto editorial SM-Enlace (cuadro 7), la noción de adjetivo remite solo a los adjetivos calificativos, a los que se dedica el apartado gramatical de una unidad (unidad 6), tras la dedicada a los determinantes y sus tipos (unidad 5). Desde el primer curso se trabaja con la perspectiva forma-significado-función y se incorporan informaciones de uso, situadas en pequeños recuadros a la izquierda de las explicaciones, lo que indica su carácter complementario. En el manual de $\mathrm{I}^{\mathrm{o}}$ de ESO, se incorpora un recuadro de norma referido a la concordancia del adjetivo con grupos nominales de más de un sustantivo de distinto género y otro referido a los valores simbólicos de los adjetivos de colores en la cultura occidental. Ninguno de estos aspectos tiene reflejo en las actividades, lo que refuerza su carácter complementario (y anecdótico).

Cuadro 7. El adjetivo como contenido gramatical explícito en $\mathrm{I}^{\circ} \mathrm{ESO}$ (proyecto SM-Enlace)

\begin{tabular}{|c|c|c|c|c|c|}
\hline Adjetivo & Definición & Tipos/Clases & Características & Uso & Actividades de aprendizaje \\
\hline $\begin{array}{l}\text { Proyecto } \\
\text { SM-Enlace } \\
\text { Io ESO } \\
\text { (unidad 6, } \\
\text { pp. Io6- } \\
\text { I09) }\end{array}$ & $\begin{array}{l}\text { «Es una } \\
\text { palabra que } \\
\text { complementa } \\
\text { al nombre, } \\
\text { expresa una } \\
\text { cualidad o } \\
\text { propiedad de } \\
\text { ese nombre } \\
\text { y concuerda } \\
\text { con él en } \\
\text { género y } \\
\text { número.» } \\
\text { (unidad 6, } \\
\text { p. Io6) }\end{array}$ & $\begin{array}{l}\text { Solo se } \\
\text { consideran } \\
\text { los adjetivos } \\
\text { calificativos. } \\
\text { La } \\
\text { clasificación } \\
\text { de los } \\
\text { calificativos } \\
\text { se hace } \\
\text { según las } \\
\text { características } \\
\text { de forma y } \\
\text { significado } \\
\text { (siguiente } \\
\text { columna) }\end{array}$ & $\begin{array}{l}\text { - Forma: género } \\
\text { (adjetivos de } \\
\text { una o dos } \\
\text { terminaciones) } \\
\text { y número. } \\
\text { Concordancia. } \\
\text {-Significado: } \\
\text { explicativos, } \\
\text { especificativos. } \\
\text { - Grados: } \\
\text { positivo, } \\
\text { comparativo, } \\
\text { superlativo. } \\
\text { - Función: } \\
\text { dentro del } \\
\text { grupo nominal, } \\
\text { complemento } \\
\text { del nombre y } \\
\text { atributo. }\end{array}$ & $\begin{array}{l}\text { Recuadros a } \\
\text { la izquierda } \\
\text { de las } \\
\text { explicaciones: } \\
\text { - Norma: } \\
\text { concordancia } \\
\text { con grupos } \\
\text { nominales } \\
\text { de dos } \\
\text { elementos } \\
\text { de distinto } \\
\text { género } \\
\text { (p. Io6) } \\
\text { - Adjetivos de } \\
\text { colores: se } \\
\text { afirma que } \\
\text { son los más } \\
\text { utilizados y } \\
\text { se informa } \\
\text { de sus valores } \\
\text { simbólicos en } \\
\text { la tradición } \\
\text { occidental. } \\
\text { (p. Io8) }\end{array}$ & $\begin{array}{l}\text { - Identificar adjetivos en un } \\
\text { fragmento narrativo. } \\
\text { - Agrupar adjetivos por } \\
\text { su significado (estados } \\
\text { de ánimo, formas de } \\
\text { objetos, descripción física, } \\
\text { descripción de carácter, } \\
\text { sensaciones). } \\
\text { - Escribir adjetivos que } \\
\text { concuerden en género y } \\
\text { número con sustantivos } \\
\text { dados o con variaciones de } \\
\text { grado establecidas. } \\
\text { - Distinguir adjetivos de una } \\
\text { o dos terminaciones. } \\
\text { - Clasificar adjetivos en } \\
\text { explicativos y especificativos } \\
\text { según su posición en frases } \\
\text { dadas, o según su grado. } \\
\text { - Escribir adjetivos a partir } \\
\text { de definiciones, en un } \\
\text { crucigrama, o según su } \\
\text { grado, en oraciones dadas. } \\
\text { - Identificar la función } \\
\text { sintáctica de adjetivos en } \\
\text { oraciones dadas; sustituir } \\
\text { grupos preposicionales } \\
\text { por adjetivos en grupos } \\
\text { nominales. }\end{array}$ \\
\hline
\end{tabular}


Si sintetizamos cómo progresan los contenidos gramaticales sobre el adjetivo en los manuales de $\mathrm{I}^{\mathrm{O}}$ a $4^{\circ}$ de ESO (proyecto editorial SM-Enlace), en primer lugar hay que señalar que, a diferencia del proyecto anterior, la noción de adjetivo se utiliza solo para los adjetivos calificativos. Hay coincidencia, en cambio, en definir la noción a partir de forma, significado y función, en este caso desde el manual de $\mathrm{I}^{\mathrm{o}}$ (cuadro 8) y también, básicamente, en los contenidos de forma (variación de género y número, grado) y de significado (explicativos y especificativos). La progresión de la noción se centra en el comportamiento sintáctico del término y aquí es donde se observa un planteamiento que resulta complicado y equívoco. Aparece el adjetivo como elemento del grupo nominal cuyas funciones básicas son complemento del nombre, atributo y complemento predicativo. Pero además, y sin mayores precisiones, se introduce el término grupo adjetival y la noción de complemento del adjetivo. Para mayor complicación, se habla de oraciones de relativo, proposiciones relativas, proposiciones adjetivas y proposiciones subordinadas adjetivas, dando por hecho que el alumno relacionará estos términos como equivalentes.

Como en el proyecto anterior, las actividades son básicamente de identificación y de manipulación de las características del adjetivo en el marco de la palabra o de la oración. No hay alusiones al uso de los adjetivos (salvo en aspectos normativos) ni a su valor comunicativo, aunque sí hay mayor atención a los aspectos semánticos.

Cuadro 8. Progreso de la noción de adjetivo como contenido gramatical explícito en los manuales de $\mathrm{I}^{\mathrm{o}}$ a $4^{\mathrm{o}} \mathrm{ESO}$ (SM-Enlace).

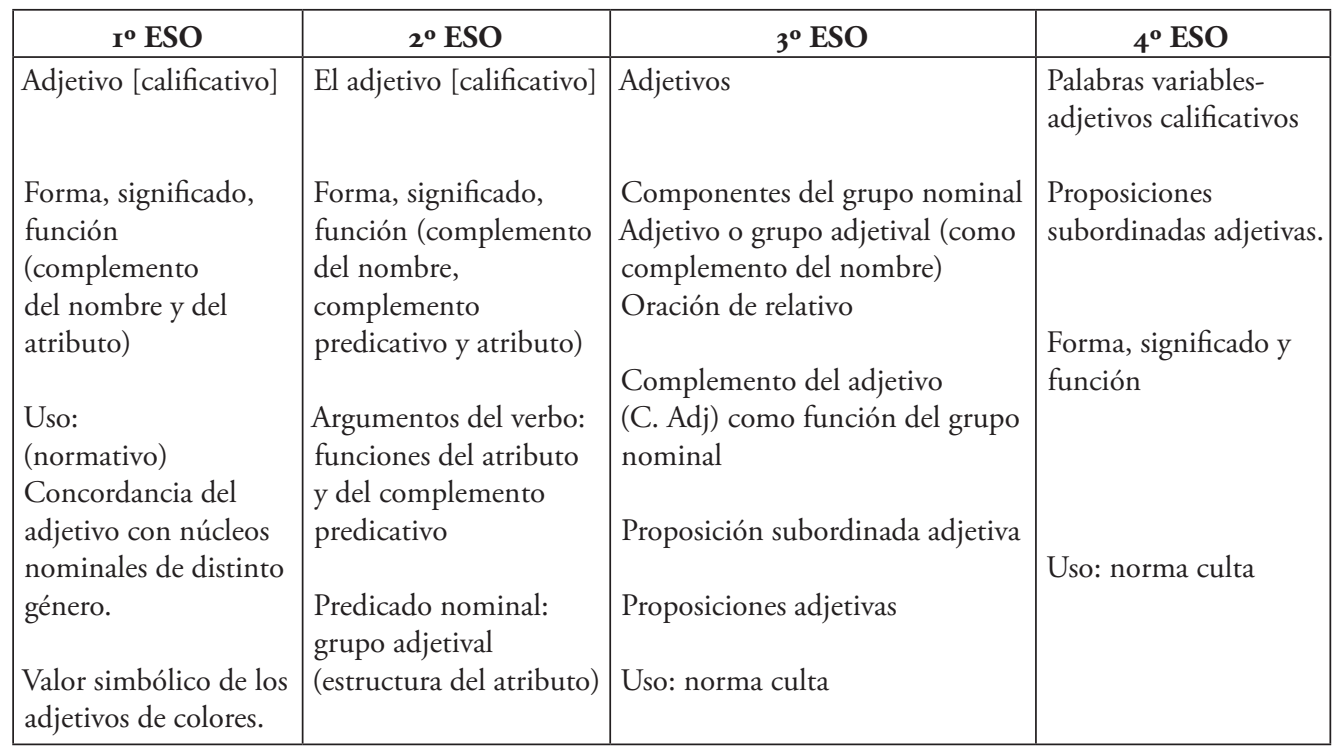




\section{DE TEXTOS EN LOS MANUALES DE ESO}

3.2 EL ADJETIVO COMO RECURSO LINGÜÍSTICO PARA EL ANÁLISIS O LA PRODUCCIÓN

Como hemos indicado antes, la organización de los contenidos en cada unidad didáctica se realiza en bloques (cuadros I y 2). Hemos mostrado con dos ejemplos referidos al adjetivo (cuadros 3 y 4 ) que los contenidos de estos bloques no presentan coordinación entre sí, de forma que el estudio del adjetivo como contenido gramatical explícito no se pone en relación, por ejemplo, con los contenidos vinculados a la descripción. Esto supone que, en los materiales, hay una clara desvinculación entre los contenidos gramaticales y los aspectos de uso.

A continuación analizamos este aspecto de forma más detallada. Para ello, rastreamos en ambos proyectos editoriales los contenidos sobre la descripción, como actividad discursiva más asociada al uso de adjetivos y nos fijamos en su relación con las unidades en que se abordaban explícitamente estos contenidos gramaticales.

Cuadro 9. Contenidos sobre descripción y sobre adjetivos

\begin{tabular}{|c|c|c|c|c|}
\hline \multirow[b]{2}{*}{ ESO } & \multicolumn{2}{|c|}{ Santillana-Proyecto La casa del saber } & \multicolumn{2}{|c|}{ SM-Proyecto Enlace } \\
\hline & $\begin{array}{l}\text { Bloque } \\
\text { Comunicación }\end{array}$ & $\begin{array}{l}\text { Bloque Estudio de la } \\
\text { lengua. Gramática }\end{array}$ & Bloque Textos & $\begin{array}{l}\text { Bloque Conocimiento de } \\
\text { la lengua. Gramática }\end{array}$ \\
\hline $\begin{array}{l}\mathbf{I}^{\mathbf{o}} \\
\text { ESO }\end{array}$ & $\begin{array}{l}\text { Unidad } 5 . \\
\text { La descripción } \\
\end{array}$ & $\begin{array}{l}\text { Unidad ıo. El adjetivo } \\
\text { calificativo } \\
\text { Unidad II. Los } \\
\text { adjetivos } \\
\text { determinativos }\end{array}$ & 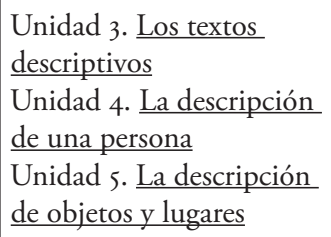 & $\begin{array}{l}\text { Unidad 6. El adjetivo } \\
\text { Unidad } 8 . \text { El grupo } \\
\text { nominal. Componentes }\end{array}$ \\
\hline $\begin{array}{l}2^{\circ} \\
\text { ESO }\end{array}$ & $\begin{array}{l}\text { Unidad } 2 . \\
\text { Narración, } \\
\text { descripción, } \\
\text { diálogo }\end{array}$ & \begin{tabular}{|l} 
Unidad 8. \\
Complementos \\
del verbo y del \\
sustantivo (atributo \\
y complemento \\
predicativo) \\
\end{tabular} & $\begin{array}{l}\text { Unidad 4. Los tipos de } \\
\text { textos }\end{array}$ & $\begin{array}{l}\text { Unidad 2. El } \\
\text { determinante. El adjetivo }\end{array}$ \\
\hline $\begin{array}{l}3^{\circ} \\
\text { ESO }\end{array}$ & $\begin{array}{l}\text { Unidad } 3 . \\
\text { La descripción }\end{array}$ & $\begin{array}{l}\text { Unidad } 5 . \text { El artículo } \\
\text { y los adjetivos } \\
\text { determinativos. }\end{array}$ & $\begin{array}{l}\text { Unidad } 4 . \text { Textos } \\
\text { descriptivos } \\
\text { Unidad } 5 . \underline{\text { La descripción }} \\
\text { científica u objetiva } \\
\text { Unidad } 6 . \text { La descripción } \\
\text { literaria o subjetiva } \\
\end{array}$ & $\begin{array}{l}\text { Unidad } 4 \text {. El grupo } \\
\text { nominal. El grupo verbal } \\
\text { Unidad I2. Proposiciones } \\
\text { subordinadas adjetivas }\end{array}$ \\
\hline $\begin{array}{l}4^{\circ} \\
\text { ESO }\end{array}$ & $\begin{array}{l}\text { Unidad I. } \\
\text { Narración, } \\
\text { descripción y } \\
\text { diálogo }\end{array}$ & $\begin{array}{l}\text { Unidad } 8 . \mathrm{La} \\
\text { subordinación adjetiva }\end{array}$ & & $\begin{array}{l}\text { Unidad 2. Las palabras } \\
\text { variables (el adjetivo) } \\
\text { Unidad 8. Proposiciones } \\
\text { subordinadas adjetivas }\end{array}$ \\
\hline
\end{tabular}


Como se puede observar en el cuadro 9, en los dos proyectos editoriales hay unidades dedicadas a la descripción, en consonancia con lo establecido en el currículo oficial correspondiente. Pero en ninguno de ellos se coordina el trabajo sobre la descripción como actividad discursiva y sobre los adjetivos como contenido gramatical explícito. Así, por ejemplo, pese a que la reflexión sobre los adjetivos es necesaria tanto al analizar como al realizar descripciones, en los dos proyectos analizados, el estudio de los adjetivos se sitúa en el bloque de gramática varias unidades después de haber introducido la descripción, en el bloque de comunicación.

Esta descoordinación, difícil de explicar con criterios didácticos, se ve reforzada por dos hechos. En primer lugar, en la caracterización de la descripción no se alude a los recursos lingüísticos como elementos configuradores de la misma. De hecho, en estas unidades, la presencia del metalenguaje gramatical es muy escasa y se relega a apartados como «el lenguaje de las descripciones» en donde se indica «En las descripciones cobran especial valor los adjetivos, los marcadores espaciales y algunos recursos que sirven para dar viveza al texto" (Santillana-La casa del saber, $\mathrm{I}^{\mathrm{o}}$ : 73). En segundo lugar, apenas aparecen menciones explícitas a los adjetivos calificativos en las actividades ni de comprensión ni de expresión. Por ejemplo, se pide que se explique el carácter descriptivo de un texto (Santillana-La casa del saber, $\mathrm{I}^{\circ}$, «Las hadas»: 82) enumerando los rasgos propios del lenguaje de las descripciones que se encuentren en él, sin mención explícita de los adjetivos.

Ya en un trabajo anterior (Ferrer \& Rodríguez 20I0: I08), a propósito de la narración, señalábamos que la atención a los elementos lingüísticos era mínima, como si fueran un añadido final a la actividad discursiva y no un elemento esencial para la misma. La misma constatación realizamos en este caso sobre la descripción. Se olvida que tener noticia de un recurso lingüístico (conocer qué es un adjetivo, por ejemplo), no es lo mismo que saber usarlo o que tener conciencia de su uso. En el aprendizaje de las actividades discursivas vinculadas al desarrollo de la expresión y la comprensión se elude la reflexión sobre los conocimientos gramaticales, que se plantean al margen del uso. Como indica Ruiz Bikandi (2010: 34):

\footnotetext{
Cuando se trata de escritura y de habla formal, no es posible un buen dominio sin una reflexión sistemática sobre la lengua. El conocimiento «inconsciente» de las reglas sirve en un nivel de uso, pero el uso elaborado y consciente precisa de una mirada atenta a las palabras y de un conocimiento gradual de las sutilezas de la expresión. Esta necesidad es particularmente acusada en las lenguas de principal uso para las personas, en las que la precisión semántica y la corrección formal tienen un gran valor social. [...] Son la manipulación y la observación reflexivas las que provocan un paso en la conciencia de la lengua.
}

Así pues, en los proyectos editoriales analizados se observa una desconexión entre los contenidos gramaticales explícitos — con un planteamiento centrado en la forma, el significado y la función - y los vinculados al uso de la lengua. Estos 
contenidos se abordan generalmente de forma deductiva: se parte de la definición y de la exposición de características, que se reconocen en ejemplos prototípicos y en actividades aisladas de identificación y de manipulación controlada. Incluso en los casos en que se acude al significado, este se utiliza como un recurso para reconocer la forma, aspecto ya señalado por Coronas (2010: II9), en su trabajo sobre las oraciones coordinadas. Por su parte, los contenidos vinculados a actividades discursivas como describir, narrar, explicar... se plantean dejando al margen los recursos lingüísticos que las identifican y obviando el metalenguaje gramatical, que parece utilizarse casi con exclusividad en el bloque de "Gramática».

\section{ELADJETIVO COMO CONTENIDO DE UNA GRAMÁTICA PEDAGÓGI- CA: USOS DEL ADJETIVO Y ACTIVIDADES GRAMATICALES}

Una gramática pedagógica ha de incluir aquellos conocimientos gramaticales relevantes para la educación lingüística de todos los estudiantes y ha de presentarlos de modo que la reflexión gramatical se oriente hacia el uso consciente de las lenguas en las diversas esferas de la actividad social. Para que esta orientación sea posible, es necesario conocer en qué géneros discursivos son relevantes las formas gramaticales objeto de observación y reflexión, y qué función tienen en ellos. Este conocimiento servirá de guía, junto con otros criterios pedagógicos (temporalización, etapa educativa...) para construir las actividades de aprendizaje (Zayas 20I2).

En el marco de este trabajo no es posible describir exhaustivamente los usos del adjetivo y sus funciones en las diversas clases de textos. Así que nos limitaremos a algunos ejemplos exploratorios, que muestren la necesidad de ir más allá de la descripción descontextualizada que nos proporcionan las gramáticas. En relación con ellos, mostramos modelos de actividades gramaticales que ponen el acento en el uso y que se apartan del modelo dominante en los libros de texto. Tal y como se ha señalado en 3.I (cuadros 5 y 7), la actividad gramatical más frecuente consiste en identificar y analizar las formas lingüísticas que previamente se han mostrado y descrito, mediante ejemplos prototípicos y descontextualizados.

En el cuadro io mostramos algunos usos del adjetivo y un repertorio de actividades de reflexión gramatical en relación con ellos. ${ }^{5}$ En la columna de la izquierda, partimos de la división en calificativos y relacionales de la $N G B L E$. En la columna de la derecha, ejemplificamos los tres grandes bloques de actividades (de comprensión,

5. Una versión previa de esta figura, para Primaria, puede consultarse en Rodríguez Gonzalo (20I5). 
Carmen Rodríguez-Gonzalo \& Felipe Zayas

La relación entre conocimientos gramaticales y el aprendizaje

de prácticas discursivas: el adjetivo como ejemplo

de composición y de manipulación) que permiten la reflexión sobre los contenidos gramaticales y la apropiación de los mismos. En los epígrafes siguientes (4.I. a 4.6) desarrollamos algunos de estos casos. ${ }^{6}$

Cuadro Io. Usos de los adjetivos y actividades gramaticales (elaboración propia)

\begin{tabular}{|c|c|}
\hline $\begin{array}{c}\text { USOS DEL ADJETIVO } \\
\text { (para qué usamos los adjetivos y dónde } \\
\text { encontramos estos usos) }\end{array}$ & $\begin{array}{c}\text { ACTIVIDADES DE REFLEXIÓN GRAMATICAL } \\
\text { (uso reflexivo del adjetivo en actividades } \\
\text { de enseñanza y aprendizaje) }\end{array}$ \\
\hline $\begin{array}{l}\text { Para CALIFICAR } \\
\text { I. Títulos de relatos, de libros, de canciones, de } \\
\text { películas: } \\
\text { La increible y triste historia de la cándida Eréndira } \\
\text { y su abuela desalmada } \\
\text { 2. Descripciones literarias: retratos } \\
\text { El capitán es un hombre pequeño, de tez rojiza, ojos } \\
\text { claros y la nariz encarnada por el alcohol } \\
\text { 3. Hechos sucedidos en relatos: Llegó un mal día... } \\
\text { 4. Sentimientos de los personajes en boca del } \\
\text { narrador: } \\
\text { «Me libré por los pelos», dijo Alicia, bastante } \\
\text { asustada... o en acotaciones teatrales: Manolita.- } \\
\text { (Despectiva) "Hombre, claro. Si el otro es un niño } \\
\text { de pecho» } \\
\text { 5. Definiciones (en enciclopedias, diccionarios, } \\
\text { libros de texto...) } \\
\text { Serpiente: Reptil ofidio sin pies, de cuerpo } \\
\text { aproximadamente cilindrico y muy largo respecto } \\
\text { de su grueso; cabeza aplanada, boca grande y } \\
\text { piel pintada simétricamente con colores diversos, } \\
\text { escamosa [...] } \\
\text { 6. Listas con diferentes finalidades (en relatos y } \\
\text { poemas, en catálogos comerciales...) } \\
\text { [en un relato] habia ordenado diferentes objetos: } \\
\text { una postal que reproducía un cuadro de Paolo } \\
\text { Ucello [...]; una flor seca y azul; una vieja caja } \\
\text { china... } \\
\text { 7. Titulares de prensa } \\
\text { Partido impresionante } \\
\text { Garcia Márquez dejó un valioso legado } \\
\text { 2. Eslóganes publicitarios o políticos } \\
\text { Semana fantástica } \\
\text { Por el pleno empleo }\end{array}$ & $\begin{array}{l}\text { COMPRENSIÓN LECTORA: } \\
\text { - Identificar los adjetivos mediante los que el } \\
\text { narrador describe los sentimientos expresados por los } \\
\text { personajes en un relato. } \\
\text { - Identificar los adjetivos que indican la valoración que } \\
\text { se hace de una noticia o de un objeto publicitado. } \\
\text { - Esquematizar una explicación sobre tipos de } \\
\text { animales, de materia, de plantas... diferenciados por } \\
\text { adjetivos (animales herbivoros, carnívoros, omnivoros). } \\
\text { - Identificar las distintas informaciones que aparecen } \\
\text { en las definiciones de adjetivos en diccionarios } \\
\text { (abreviaturas de clase de palabras y de usos específicos, } \\
\text { sinónimos, variación de género...). } \\
\text { - Analizar definiciones de adjetivos valorativos y de } \\
\text { adjetivos relacionales en diccionarios para observar } \\
\text { los patrones seguidos en cada caso. } \\
\text { COMPOSICIÓN DE TEXTOS: } \\
\text { - Elaborar retratos de personajes literarios o de } \\
\text { actualidad mediante la construcción de enunciados } \\
\text { que siguen patrones sintácticos determinados. } \\
\text { - Elaborar anuncios con eslóganes publicitarios que } \\
\text { incluyan adjetivos de valoración. } \\
\text { - Elaborar definiciones con ayuda de la explicación del } \\
\text { adjetivo en el diccionario: Un animalvivíparo es el que... } \\
\text { - Elaborar listas en contextos que les den sentido (relatos, } \\
\text { poemas, catálogos...) } \\
\text { - Redactar titulares, a partir de breves entradas de } \\
\text { noticias, con grupos nominales en los que haya un } \\
\text { adjetivo relacional. } \\
\text { - Redactar definiciones de adjetivos sin ayuda } \\
\text { de diccionario, siguiendo patrones gramaticales } \\
\text { establecidos. }\end{array}$ \\
\hline
\end{tabular}

6. Señalamos en negrita los usos para los que se proponen actividades. 
Carmen Rodríguez-Gonzalo \& Felipe Zayas

La relación entre conocimientos gramaticales y el aprendizaje de prácticas discursivas: el adjetivo como ejemplo

\begin{tabular}{|c|c|}
\hline $\begin{array}{l}\text { Para CLASIFICAR } \\
\text { 9. Explicaciones académicas (libros de texto, } \\
\text { enciclopedias...) } \\
\text { Animales viviparos / ovíparos } \\
\text { Energía eléctrica / mecánica } \\
\text { IO. Catálogos comerciales, señalización en } \\
\text { establecimientos } \\
\text { Calzado infantil } \\
\text { Bebidas refrescantes } \\
\text { II. Guías (turísticas, de plantas, de animales...) } \\
\text { Restaurante mexicano } \\
\text { Aves rapaces }\end{array}$ & $\begin{array}{l}\text { MANIPULACIÓN: } \\
\text { - Cambiar la valoración de titulares de prensa } \\
\text { modificando los adjetivos (por ejemplo, de crónicas } \\
\text { deportivas) } \\
\text { - Modificar grupos nominales con adjetivo por } \\
\text { expresiones equivalentes (complementos con de): } \\
\text { Plantas acuáticas por Plantas de agua. }\end{array}$ \\
\hline
\end{tabular}

\section{I EL ADJETIVO EN LAS DESCRIPCIONES LITERARIAS: EL RETRATO}

Dado que el adjetivo calificativo denota cualidades o propiedades que se agregan al significado del sustantivo, esta clase de palabra tiene un importante papel en las descripciones (de personas, de paisajes, de ambientes, de objetos, etc.). Nos conviene por tanto averiguar qué comportamiento tiene el adjetivo en actividades discursivas de este tipo. Nos limitaremos aquí al retrato.

Los retratos pueden ser de una gran sencillez, ejecutados con muy pocos elementos, seleccionados para trazar una imagen expresiva del personaje descrito, como en las variantes del ejemplo i:

\section{Ejemplo I}

Ia. El seńor Fleuri era un hombre afeitado y serio, con el pelo blanco, muy bien vestido y de aspecto malhumorado. (P. Baroja, La ciudad de la niebla)

Ib. El chófer me espía por el retrovisor. Es pelirrojo, pecoso, de cejas anchas, y ojos saltones, oscuros. (J. Goytisolo, Campos de Nijar)

Ic. Una mujer trajina al otro lado del mostrador [...] Como muchas mujeres del país, tiene el cabello negro y la tez muy blanca, la boca de trazo regular, y los ojos azules, impregnados de melancólica tristeza. (J. Goytisolo, Campos de Nijar) 
Carmen Rodríguez-Gonzalo \& Felipe Zayas

La relación entre conocimientos gramaticales y el aprendizaje

de prácticas discursivas: el adjetivo como ejemplo

Pero pueden constituir textos de una gran complejidad, como ocurre con el ejemplo 2, la descripción del dómine Cabra, uno de los retratos más conocidos de la tradición literaria. ${ }^{7}$

Ejemplo 2

Él era un clérigo cerbatana, largo solo en el talle, una cabeza pequeña, pelo bermejo [...], los ojos avecinados en el cogote, que parecía que miraba por cuévanos [...]; la nariz, entre Roma y Francia [...]; las barbas descoloridas de miedo de la boca vecina [...]; los dientes, le faltaban no sé cuántos [...]; el gaznate largo como de avestruz [...]; los brazos secos, las manos como un manojo de sarmientos cada una.

En los enunciados del ejemplo I, observamos estas tres construcciones sintácticas:

a) Sujeto + verboSER + atributo (grupo nominal): Elseñor Fleuri era un hombre afeitado (ejemplo ra). Nótese que el adjetivo calificativo es un complemento dentro del grupo nominal, que tiene la función de atributo. En este grupo sintáctico aparecen otros complementos del nombre con la forma gramatical de grupo preposicional y también con una función descriptiva.

b) Sujeto + verboSER + atributo (grupo adjetival): Elchóferespelirrojo (ejemplo Ib). La función de atributo está desempeñada por un adjetivo calificativo, y forma parte generalmente de una serie de grupos (adjetivales y preposicionales) con la misma función.

c) Sujeto + verbo TENER + CD + predicativo: La mujer tiene el cabello negro (ejemplo Ic). El adjetivo calificativo desempeña la función de predicativo. Generalmente aparecen series de complementos directos y sus correspondientes predicativos.

Los patrones descriptivos que se acaban de examinar contrastan con retratos mucho más complejos, como el que se incluye en el ejemplo 2, que examinaremos a continuación. A partir de una cabeza pequeña, la sucesión de enunciados sigue el esquema de progresión temática de temas derivados (figura I): un tema general o hipertema (en este caso, la persona descrita) da lugar a diferentes subtemas con sus remas respectivos. (Calsamiglia \& Tusón 2007: 23I). La función informativa de tema está desempeñada por las palabras que denotan las partes del cuerpo descritas y la del rema se refiere a las cualidades y propiedades de estas partes. Sintácticamente, estas de Buen Amor.

7. Este mismo patrón descriptivo aparece en el conocido autorretrato del Arcipreste de Hita en el Libro 
Carmen Rodríguez-Gonzalo \& Felipe Zayas

dos funciones informativas se corresponden generalmente con las funciones sintácticas de sujeto y de atributo en una construcción que puede ser verbal (es su cuerpo muy ancho) o no verbal (sus cejas, apartadas, los ojos avecinados en el cogote).

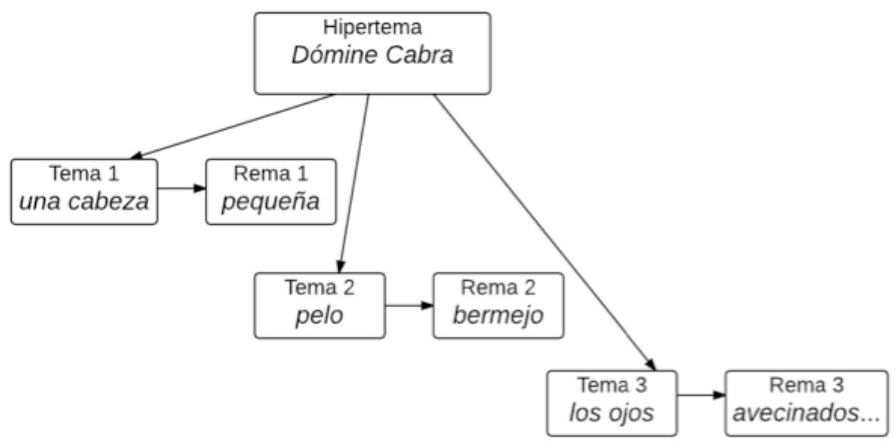

Figura I. Progresión temática de temas derivados (elaboración propia).

Conocer los esquemas sintácticos y textuales de los retratos permite precisar mejor las pautas para su composición y para el uso reflexivo de los adjetivos desde la perspectiva textual. Algunas de las pautas que se pueden proporcionar son:

- Construcción de enunciados siguiendo los patrones sintácticos examinados más arriba, previo el examen de modelos.

- Transformación de construcciones sintácticas con TENER en construcciones con SER y viceversa:

Tenía un rostro...; tenía un cabello...; tenía una frente... > Su rostro... su cabello...; su frente...

- Conversión de una construcción con verbo copulativo en una oración con verbo no copulativo:

Su cabello era largo y negro y le cubría los hombros > Su cabello, largo y negro, le cubría los hombros.

4.2 LOS ADJETIVOS EN RELATOS Y TEXTOS DRAMÁTICOS PARA CARACTERIZAR LOS SENTIMIENTOS DE LOS PERSONAJES

En los relatos, el narrador cuenta qué hacen los personajes y, como ya hemos visto, los describe con diferentes procedimientos. Pero también nos informa de cómo se sienten cuando actúan, por ejemplo, cuando hablan: 
Carmen Rodríguez-Gonzalo \& Felipe Zayas

La relación entre conocimientos gramaticales y el aprendizaje

de prácticas discursivas: el adjetivo como ejemplo

Ejemplo 3

«Me libré por los pelos», dijo Alicia, bastante asustada por tan súbita transformación, pero muy contenta al verse aún viva. ${ }^{8}$ (L. Carroll, Alicia en el País de las Maravillas)

Esta información sobre los sentimientos expresados por los personajes también la encontramos en los textos dramáticos, mediante las acotaciones:

Ejemplo 4

Manolita.-(Despectiva.) Hombre, claro. Si el otro es un niño de pecho. (F. Fernán Gómez:

Las bicicletas son para el verano)

En ambos ejemplos, la información sobre el estado de ánimo o actitud del personaje la proporciona un adjetivo. En la narración (ejemplo 3), este adjetivo (o mejor, el grupo adjetival completo) tiene la función de complemento predicativo; en el texto dramático (ejemplo 4), el adjetivo constituye un enunciado no oracional.

Identificar los adjetivos mediante los que el narrador describe los sentimientos expresados por los personajes cuando hablan puede formar parte de ejercicios de comprensión lectora. Pero también, de las instrucciones incluidas en un taller de composición de relatos, de modo que los alumnos no se limiten a usar los verbos dijo, contestó, respondió, etc., sino que se vean invitados a usar un adjetivo predicado del sujeto que denote el sentimiento que corresponda, como se ha mostrado en el ejemplo 3 .

Esta observación de los relatos es imprescindible si se trabaja en la transformación de un texto narrativo en un texto dramático, en el que la información sobre el personaje, que en el relato proporciona el narrador, se indicará en forma de acotación (Zayas 1996).

\subsection{LOS ADJETIVOS EN LAS DEFINICIONES}

Para examinar el uso del adjetivo en textos informativos hemos utilizado algunas entradas del Diccionario de la Lengua $(D L E)$ correspondientes a definiciones de plantas y animales (ejemplos $5 \mathrm{a}-5 \mathrm{~d}$ ). Se observa en ellas el uso abundante de adjetivos calificativos (junto con algún ejemplo de adjetivos relacionales: planta anual). Con ellos no se busca expresar impresiones y sentimientos suscitados por la observación de personas o paisajes, sino la precisión en la descripción.

8. Los subrayados son nuestros. 
Ejemplo sa

Amapola

Planta anual de la familia de las papaveráceas, con flores rojas por lo común y semilla negruzca. Frecuentemente nace en los sembrados y los infesta. [...]

Ejemplo $5 \mathrm{~b}$

Junco

Planta de la familia de las juncáceas, con tallos de 60 a $80 \mathrm{~cm}$ de largo, lisos, cilíndricos, flexibles, puntiagudos, duros, y de color verde oscuro por fuera y esponjosos y blancos en el interior. [...]

Ejemplo 5c

Gorrión

Pájaro de unos doce centímetros desde la cabeza a la extremidad de la cola, con el pico fuerte, cónico y algo doblado en la punta; plumaje pardo en la cabeza, castańo en el cuello, espalda, alas y cola, pero con manchas negras y rojizas, ceniciento en el vientre; en el macho, con babero negro en pecho y garganta. [...]

Ejemplo 5d

Serpiente

Reptil ofidio sin pies, de cuerpo aproximadamente cilíndrico y muy largo respecto de su grueso; cabeza aplanada, boca grande y piel pintada simétricamente con colores diversos, escamosa, y cuya parte externa o epidermis muda por completo el animal de tiempo en tiempo. $[\ldots]$

Importa señalar, además de la variedad de significados denotados por los adjetivos calificativos de estos textos, algunas de sus características morfológicas:

- Adjetivos de color formados por derivación de otros adjetivos: negruzco, rojizo (ejemplos 5a, 5c).

- Adjetivos que describen la forma construidos por derivación a partir de nombres de figuras geométricas: cilíndrico, cónico (ejemplos 5b, 5c, 5d).

- Adjetivos que describen la densidad construidos por derivación a partir de sustantivos que denotan seres con la cualidad que se describe: esponjosos (ejemplo 5b).

- Adjetivos formados por composición: puntiagudo (ejemplo 5b). 
Carmen Rodríguez-Gonzalo \& Felipe Zayas

La relación entre conocimientos gramaticales y el aprendizaje

de prácticas discursivas: el adjetivo como ejemplo

También se podrían encontrar, si ampliáramos los ejemplos, adjetivos formados por derivación o por composición a partir de nombres de objetos que tienen como característica la forma que se quiere describir: almendrado, filiforme, etc.

Las definiciones examinadas ofrecen la oportunidad de observar los mecanismos de la morfología derivativa para formar adjetivos que describen el color, la forma o figura, la dimensión la densidad y la dureza. La observación incluye:

- La clasificación de los adjetivos según la cualidad denotada (color, forma, dimensión, densidad y consistencia, dureza, etc.).

- La categoría gramatical de la palabra que sirve de base para la derivación y de la palabra derivada.

- Los sufijos usados para la formación de la palabra derivada.

- Las palabras que intervienen en la composición y su categoría gramatical.

Además de estas observaciones, convendrá usar los mecanismos examinados en definiciones que los alumnos pueden redactar a partir de los modelos propuestos.

\subsection{LA DEFINICIÓN DEL ADJETIVO EN LOS DICCIONARIOS}

Obviamente, los adjetivos se usan también en los diccionarios, como voces que se definen. ¿Cuál es el patrón gramatical de la definición del adjetivo? Existen dos, según que el adjetivo sea calificativo o de relación:

Ejemplo 6

6a. indeciso: perplejo, irresoluto, que tiene dificultad en decidirse.

6b. muscular: perteneciente o relativo a los músculos.

Como se ve, los adjetivos calificativos se definen mediante sinónimos y mediante una paráfrasis con una oración de relativo (6a). En cambio, los adjetivos de relación se definen mediante la fórmula "perteneciente o relativo a» (6b).

Será útil proponer a los alumnos que busquen en el diccionario definiciones de adjetivos que sigan estos dos modelos. Esta actividad tiene sentido como parte de ejercicios de comprensión lectora, y no como una búsqueda de palabras fuera de contexto. Como ejercicio de composición, se puede plantear la redacción de definiciones, sin ayuda del diccionario, tal como se propone en las definiciones de conceptos en diversas materias. 


\subsection{LOS ADJETIVOS EN LAS LISTAS}

Las listas, con diferentes finalidades, son frecuentes en los relatos y en los poemas. Examinemos la del ejemplo 7:

Ejemplo 7

Sobre una mesita de madera, cubierta con un paño de terciopelo ocre, [Elsa] había ordenado diferentes objetos: una postal que reproducía un cuadro de Paolo Ucello: san Jorge y el dragón; una flor seca y azul que, según decía, se llamaba "Love in a mist»; una vieja caja china con una fotografía suya y la copia de todas las cartas que había enviado a Agustín Valdés. (A. García Morales. El silencio de las sirenas)

Las entidades que se enumeran están representadas por grupos nominales, cuyo núcleo está acompańado de modificadores con diferente forma gramatical: grupos adjetivales, grupos preposicionales, oraciones de relativo... En el ejemplo 6, algunos de los sustantivos que denotan los objetos de la lista están complementados por varios modificadores (una vieja caja china con una fotografía suya).

La enumeración de objetos de las listas permite observar la equivalencia funcional de complementos del nombre con diferente forma gramatical, así como la asimetría en cuanto a su proximidad con el nombre cuando este va acompańado de varios modificadores. Así, en una vieja caja china con una fotografía suya, el núcleo del grupo nominal está acompañado de tres complementos: vieja (adjetivo calificativo), china (adjetivo relacional), con una fotografía suya (grupo preposicional). El que tiene mayor vinculación con el núcleo es el adjetivo relacional, por lo que vieja complementa al grupo caja china y el grupo preposicional con una fotografía suya complementa al grupo vieja caja china.

Estas observaciones deberán ir seguidas de prácticas de composición de listas dentro de contextos que les den sentido: alguien entra en una habitación en desorden y enumera los objetos que hay repartidos aquí y allá; en un trayecto en bicicleta, se enumeran las cosas que se van viendo; etc. El texto producido por los alumnos será un buen material para observar la diferente naturaleza gramatical de los diferentes complementos del nombre utilizados.

\subsection{LOS ADJETIVOS EN LOS TITULARES DE PRENSA}

En el ejemplo 8 se recogen titulares informativos tomados de la edición digital de El País. Se ha podido constatar, a partir de los resultados de esta búsqueda, la 
Carmen Rodríguez-Gonzalo \& Felipe Zayas

La relación entre conocimientos gramaticales y el aprendizaje

de prácticas discursivas: el adjetivo como ejemplo

abundancia de titulares en los que aparecen adjetivos relacionales. En cambio, son bastantes menos los ejemplos de adjetivos calificativos en titulares informativos, y de ellos solo algunos sirven para expresar un significado valorativo: Gasol, a la altura de los grandes mitos europeos; Los refugiados afrontan crecientes obstáculos en su camino europeo.

¿Cómo son los adjetivos de relación encontrados? Una parte son gentilicios europeos, hispanos, mediterráneo-, otros son clasificatorios: homosexual, militar, plegable. En los titulares encontrados no aparece ningún ejemplo de adjetivos con algún papel argumental, pero podrían encontrarse casos como discurso presidencial.

Ejemplo $8^{9}$

8a. Mas quiere un 27-S con observadores internacionales.

8b. EE UU acepta negociar con Rusia una solución militar en Siria.

8c. Rajoy y la cúpula del PP festejan el matrimonio homosexual de Maroto.

8d. Florida presume de raíces hispanas.

8e. Las averías no eximen a las líneas aéreas de pagos de comisiones.

8f. Los Emy premian por primera vez una película de realidad virtual.

$8 \mathrm{~g}$. El sorprendente «Smartphone» con pantalla plegable.

8h. El Papa inicia en Cuba una visita política e imprevisible.

8i. Expertos alertan de los peligros desconocidos de los tatuajes.

8 j. Gasol, a la altura de los grandes mitos europeos.

(El País, I9 de septiembre de 20I5)

A partir de breves entradas de noticias, se puede proponer a los alumnos que redacten titulares formados por grupos nominales o preposicionales en los que haya un adjetivo relacional; por ejemplo:

Entrada: Oceanógrafos británicos enviaron botellas con mensajes hace iıo años. Una anciana alemana ha encontrado una de ellas.

Titular: Un mensaje centenario en una botella

Una variante más sencilla es dar el titular original, pero sin el adjetivo, para que los alumnos lo deduzcan a partir de la información de la entrada.

En conclusión, este apartado concreta cómo entendemos la relación didáctica entre conocimiento gramatical y usos discursivos, tomando como ejemplo la noción de

9. Los subrayados son nuestros. 
adjetivo, ${ }^{10}$ como alternativa al planteamiento desvinculado que aparece con frecuencia en los libros de texto, tal como hemos mostrado en el apartado 3.

Para ello, hemos partido de la exploración de los contextos discursivos de los que forman parte los adjetivos y hemos tipificado las actividades de reflexión gramatical - de comprensión, de expresión y de manipulación-que permiten incorporar estos usos al aula (cuadro Io). A continuación, en los subapartados siguientes hemos desarrollado estas actividades, a partir de ejemplos de ámbitos de uso diferentes (literatura, mundo académico, medios de comunicación...). En todos los casos podemos observar cómo los tres tipos de actividades se interrelacionan (la composición de textos necesita de análisis y manipulación previa del comportamiento gramatical de los adjetivos) y cómo el trabajo sobre una noción gramatical a través de sus usos necesita relacionar aspectos semánticos y sintácticos en la mayoría de los casos (4.I, 4.2, 4.4, 4.5 y 4.6), o aspectos semánticos y morfología derivativa en 4.3. Al tratarse de enunciados que forman parte de usos reales, la dimensión discursivo-textual está siempre presente, lo que ayuda a la significatividad del aprendizaje.

\section{EL ADJETIVO EN UNA GRAMÁTICA PEDAGÓGICA: CRITERIOS DE PROGRESIÓN}

El planteamiento didáctico mostrado se ha de completar con los criterios de progresión. No es nuestro propósito establecer aquí una gradación cerrada de la enseñanza-aprendizaje del adjetivo, lo que no es posible de forma aislada. Nos limitaremos a apuntar algunos criterios que complementen el planteamiento que defendemos. El análisis realizado en 3.I muestra que la progresión del tratamiento del adjetivo en los dos proyectos editoriales analizados (cuadros 6 y 8 ) se basa en la perspectiva de forma-significado-función y que en este planteamiento no se tienen en cuenta los usos discursivos. Pretendemos aquí ofrecer tres criterios alternativos, en la línea de la gramática pedagógica que postulamos.

El primer criterio de progresión, si hablamos de una gramática relacionada con el uso, remite a la presencia ineludible de dos ejes complementarios: el gramatical (forma-significado-función) y el discursivo, es decir, los géneros y las actividades discursivas en que el adjetivo es necesario, como mostramos en el cuadro io.

IO. En relación con la noción de verbo, puede consultarse también Zayas (20I7). 
Carmen Rodríguez-Gonzalo \& Felipe Zayas

La relación entre conocimientos gramaticales y el aprendizaje

de prácticas discursivas: el adjetivo como ejemplo

En el caso del eje gramatical, la presencia simultánea de adjetivos calificativos y relacionales desde los primeros cursos (puerta anchalpuerta metálica) permite abordar inicialmente su especificidad semántica junto a los aspectos morfosintácticos comunes (concordancia de género y número) y avanzar luego en sus diferencias de morfología flexiva y de sintaxis.

En el caso del eje discursivo, la progresión viene determinada por la proximidad de los usos a la vida de los hablantes y por la complejidad sintáctico-discursiva de los mismos, condicionada a su vez, por la complejidad del mundo que queremos representar con el lenguaje. Así, por ejemplo, la presencia del adjetivo en los títulos tiene distinta complejidad sintáctico-discursiva en El sastrecillo valiente o La ratita presumida frente a La increíble y triste historia de la cándida Eréndira y su abuela desalmada. Lo mismo se puede decir de las descripciones de personajes en los relatos, como se muestra en 4.I.

Entendemos, pues, que la apropiación de un concepto (en este caso, el adjetivo) implica la progresiva captación de su complejidad, progresión que no implica postergar aspectos constitutivos del mismo.

El segundo criterio, complementario del anterior, es que las decisiones de progresión en todos los cursos afectan a ambos ejes, el gramatical y el discursivo. Cabe preguntarse entonces cuáles pueden ser criterios de avance. En este sentido, si tomamos como referencia los contenidos gramaticales sintetizados en el apartado 2, una primera fase sería el adjetivo (calificativo o relacional) como modificador del nombre o como atributo, lo que implica variaciones flexivas en usos discursivos de poca complejidad composicional (títulos, catálogos, etiquetas, descripciones sencillas de personajes, de estructura enumerativa...). En fases sucesivas, las manipulaciones sobre los mecanismos de formación de palabras, permitirían ahondar en las diferencias entre calificativos y relacionales y en su diferente comportamiento sintáctico (observable en definiciones y descripciones no literarias, entre otros usos).

En tercer lugar, consideramos que buena parte de la progresión en la apropiación de cualquier concepto reside en su utilización. En este sentido, es crucial la combinación de los criterios anteriores con el tipo de actividades de enseñanza-aprendizaje realizadas en el aula. De ahí que, en el cuadro io, planteemos tres tipos, que han de estar presentes en cada fase: actividades de análisis, vinculadas a la enseñanza de la comprensión lectora; actividades de composición y actividades de manipulación. Entre el análisis y la composición hay que establecer, en todos los cursos, puentes (las transformaciones, la composición con imitación de modelos, la reflexión sobre aspectos gramaticales de la propia composición) que permitan a los estudiantes el paso del uso espontáneo al uso reflexivo. Estos criterios no resuelven por sí solos el problema de la progresión, cuya complejidad requeriría de un trabajo específico, pero apuntan las vías para afrontarlo. 


\section{CONCLUSIONES}

En este trabajo, que se ocupa de la reflexión gramatical y su vinculación con el aprendizaje del uso lingüístico, hemos tomado como referencia el adjetivo, noción gramatical presente en todos los currículos escolares de lenguas y conocimiento gramatical básico en la cultura común, con el objetivo de explorar sus posibilidades didácticas en un planteamiento de la enseńanza de la gramática que vincule la reflexión gramatical con el aprendizaje del uso lingüístico. Hemos ejemplificado este planteamiento en relación con la materia de Lengua castellana y Literatura en un contexto de lengua inicial del alumnado.

El análisis realizado del tratamiento del adjetivo en la Nueva gramática básica de la lengua española nos muestra la gran importancia concedida a la dimensión semántica, así como su relación con los aspectos morfológicos y sintácticos, lo que convierte este manual en un instrumento muy útil para vincular la reflexión gramatical con las actividades de comprensión y composición de textos. Especialmente relevante es la importancia de la morfología léxica (formación de palabras) y, sobre todo, de la distinción entre adjetivos calificativos y relacionales, por sus claras diferencias en los usos de esta categoría. Consideramos que esta aproximación semántica es de gran utilidad en la transposición didáctica de los contenidos escolares.

Como contenido escolar, hemos analizado la presencia del adjetivo en dos proyectos editoriales de amplia difusión. En los libros de texto analizados, el tratamiento de esta noción (y en general de todas las clases de palabras) se centra en los aspectos morfosintácticos, que aparecen desvinculados de las actividades discursivas, ya sean de comprensión o de expresión. Las actividades de aprendizaje gramatical, básicamente de identificación y aplicación con ejemplos descontextualizados, no enseñan a razonar sobre la lengua, sino a acertar con la solución esperada. Las actividades de uso lingüístico, por su parte, obvian el metalenguaje y consideran los recursos lingüísticos como añadidos, no como elementos constitutivos de las actividades discursivas. Además, en materiales como los analizados, la división de los contenidos en bloques estancos en las unidades didácticas impide el planteamiento de secuencias de enseñanza y aprendizaje en las que se relacionen los contenidos discursivos y gramaticales. Esto es especialmente importante si consideramos la influencia de los libros de texto en la actividad del aula, en el contexto educativo actual.

Tras este análisis, nuestra propuesta se basa en conectar los contenidos gramaticales con sus usos en prácticas discursivas de diferentes ámbitos (académico, literario, personal, medios de comunicación) y en plantear actividades de aprendizaje que consideren la atención a la forma y la reflexión sobre ella en actividades tanto de 
Carmen Rodríguez-Gonzalo \& Felipe Zayas

La relación entre conocimientos gramaticales y el aprendizaje

de prácticas discursivas: el adjetivo como ejemplo

comprensión como de composición o de manipulación. Así, la división entre adjetivos relacionales y calificativos nos permite entender diferencias básicas de significado (perro ladrador-perro labrador) y de uso (por ejemplo, las diferencias entre los dos adjetivos que aparecen en titulares como Gasol, a la altura de los grandes mitos europeos). Y nos permite asimismo relacionar la estructura del grupo nominal (posición sintáctica, jerarquía de los elementos) con los efectos de significado. Finalmente, apuntamos algunos criterios para enfocar la progresión en el tratamiento del adjetivo durante la escolaridad. Con todo ello perseguimos el desarrollo de la competencia metalingüística de los estudiantes y mostramos las posibilidades de una enseñanza gramatical que vaya más allá del necesario dominio de los requerimientos normativos.

En esta tarea no es suficiente tener buenas obras lingüísticas de referencia (la $N G B L E$ lo es) que faciliten la transposición didáctica, sino que han de plantearse los contenidos escolares desde la perspectiva de la enseńanza-aprendizaje. En este sentido, este trabajo presenta una propuesta que relaciona, con el adjetivo como ejemplo, las nociones gramaticales con los usos lingüísticos y con actividades que propician la reflexión sobre la lengua.

CARMEn Rodríguez-Gonzalo
Universitat de València
crodrig@uv.es
ORCID o00o-0002-8013-7503

Felipe Zayas Grup de Recerca sobre l'Ensenyament i Aprenentatge de Llengües felipezayas@gmail.com

\section{REFERENCIAS BIBLIOGRÁFICAS}

Barth, B.-M. (2004 [ia ed. 1987]) L’apprentissage de l'abstraction, París, Retz. Calsamiglia, H. \& A. Tusón (2007) Las cosas del decir, Barcelona, Ariel. [Segunda edición actualizada.]

CAmps, A. (2003a) «Seqüències didàctiques per aprendre gramàtica (SDG)», en Papers de treball, I, Departament de Didàctica de la Llengua i la Literatura, UAB.

- (coord.) (2003b) Seqüències didàctiques per aprendre a escriure, Barcelona, Graó.

- (2017) «Reflexiones sobre la enseñanza y el aprendizaje de la gramática», en A. Camps \& T. Ribas (coords.), El verbo y su enseñanza. Hacia un modelo de 
Carmen Rodríguez-Gonzalo \& Felipe Zayas

La relación entre conocimientos gramaticales y el aprendizaje de prácticas discursivas: el adjetivo como ejemplo

enseñanza de la gramática basado en la actividad reflexiva, Barcelona, Octaedro, pp. I9-3I.

Camps, A. \& X. Fontich (2003) «La construcció del coneixement gramatical dels alumnes de secundària a través de la recerca i el raonament: l'ús del pronom hi en el català oral», Articles de Didàctica de la Llengua i la Literatura, 3I, pp. 99-IIO.

Camps, A. \& F. ZaYas, coords. (2006) Secuencias didácticas para aprender gramática, Barcelona, Graó.

Coronas, R. (20I0) «Las oraciones coordinadas en los libros de texto de lengua castellana», en T. Ribas Seix (coord.), Libros de texto y enseñanza de la gramática, Barcelona, Graó, pp. II7-I34.

Ferrer, M. \& C. Rodríguez (20Io) «La lingüística del texto en los manuales de la ESO", en T. Ribas Seix (coord.), Libros de texto y enseñanza de la gramática, Barcelona, Graó, pp. 97-II6.

Fontich, X. (2006) Hablar y escribir para aprender gramática, Barcelona, HorsoriICE UB.

Guasch, O., C. Gràcia \& P. Carrasco (2004) «L'aspecte verbal en les narracions de ficció. Una reflexió interlingüística», Articles de Didàctica de la Llengua i la Literatura, 33, pp. 57-68.

GutiÉRreZ, X. (I999) «Com funcionen els relatius? Aprendre gramàtica investigant», en M. Vilà \& A. Fargas (coords.), Normativa i ús de la llengua, Barcelona, Graó, pp. 93-III.

LoE (2006) LeY ORGÁNICA 2/2006, de 3 de mayo, de Educación. BOE núm. io6, de 4 de mayo de 2006.

LOMCE (2OI3) LeY ORGÁNICA 8/20I3, de 9 de diciembre, para la mejora de la calidad educativa, BOE núm. 295, de io de diciembre de 2013.

Milian, M. \& T. Ribas (20I7) "Características de un modelo de enseñanza de la gramática», en A. Camps \& T. Ribas (coords.), El verbo y su enseñanza. Hacia un modelo de enseñanza de la gramática basado en la actividad reflexiva, Barcelona, Octaedro, pp. 187-198.

Real Academia Española (20II) Nueva gramática básica de la lengua española, Barcelona, Espasa.

- (20I4) Diccionario de la lengua española. Vigésima tercera edición, Barcelona, Espasa.

Ribas, T. \& T. Verdaguer (2006) «Gramática y uso: los conectores en los textos argumentativos», en A. Camps \& F. Zayas (coords.), Secuencias didácticas para aprender gramática, Barcelona, Graó, pp. 49-62.

Rodríguez Gonzalo, C. (20II) «La reflexión sobre la lengua y la enseñanza de la gramática», Textos de Didáctica de la Lengua y la Literatura, 58, pp. 60-73.

Caplletra 63 (Tardor, 2017), pp. 245-277 
Carmen Rodríguez-Gonzalo \& Felipe Zayas

La relación entre conocimientos gramaticales y el aprendizaje

de prácticas discursivas: el adjetivo como ejemplo

- (2012a) «La enseñanza de la gramática: las relaciones entre la reflexión y el uso lingüístico", Revista Iberoamericana de Educación, 59, pp. 87-II8.

- (2012b) «Un espai de reflexió i recerca gramatical al voltant dels temps verbals del passat a quart d'ESO", Articles de Didàctica de la Llengua i la Literatura, 57, pp. 69-85.

- (20I5) «Reflexión metalingüística y enseñanza de la gramática en Educación Primaria», en J. Mata, M. P. Núñez \& J. Rienda (coords. y eds.) Didáctica de la lengua y la literatura, Madrid, Pirámide, pp. I49-I77.

Rodríguez, C., A. MarTínez \& F. ZaYAS (1995) «La reflexión gramatical en un proyecto de escritura: Manual de procedimientos narrativos», Textos de Didáctica de la Lengua y la Literatura, 5, pp. 37-46.

Ruiz BiKANDi, U. (20IO) «El conocimiento sobre la lengua en el Decreto de Enseñanzas Mínimas de 2007", en T. Ribas Seix (coord.), Libros de texto y enseñanza de la gramática, Barcelona, Graó, pp. 33-54.

Zayas, F. (1993) «La composición de noticias», Cuadernos de Pedagogía, 216, pp. 43-45.

[También en A. Camps (coord.) (2003b), pp. I3I-I36.]

- (1996) «Reflexión gramatical y composición escrita», Culturayeducación, 2, pp. 59-66.

- (2004) «Hacia una gramática pedagógica», Textos de Didáctica de la Lengua y la Literatura, 37, pp. 16-35.

- (20II) «El lugar de la gramática en la enseñanza de la lengua», en U. Ruiz Bikandi (coord.), Lengua castellana yliteratura. Investigación, innovación y buenas prácticas, Barcelona, Graó, pp. 9I-IO6.

- (20I2) «Los géneros discursivos y la enseñanza de la composición escrita», Revista Iberoamericana de Educación, 59, pp. 63-85.

- (2017) «El verbo: diferentes perspectivas de la reflexión gramatical», en A. Camps \& T. Ribas (coords.), El verbo y su enseñanza. Hacia un modelo de enseñanza de la gramática basado en la actividad reflexiva, Barcelona, Octaedro, pp. 5I-64.

ZaYas, F. \& Rodríguez, C. (1992) «Composición escrita y contenidos gramaticales», Aula de Innovación Educativa, 2, pp. 13-16.

Zayas, F. \& Rodríguez, C. (2003) «Los libros de texto en los tiempos de la Reforma», Cuadernos de Pedagogía, 330, pp. 25-30. 
Carmen Rodríguez-Gonzalo \& Felipe Zayas

La relación entre conocimientos gramaticales y el aprendizaje de prácticas discursivas: el adjetivo como ejemplo

\section{ANEXO. RELACIÓN DE LIBROS DE TEXTOS ANALIZADOS}

\begin{tabular}{|l|l|l|}
\hline \multirow{4}{*}{$\begin{array}{l}\text { SANTILLANA. ESO. } \\
\text { Proyecto La casa del } \\
\text { saber. } 2007\end{array}$} & 1 & $\begin{array}{l}\text { Lengua y Literatura, 10 ESO. Proyecto La casa del saber. Madrid, } \\
\text { Santillana (2007) }\end{array}$ \\
\cline { 2 - 3 } & 2 & $\begin{array}{l}\text { Lengua y Literatura, 20 ESO. Proyecto La casa del saber. Madrid, } \\
\text { Santillana (2007) }\end{array}$ \\
\cline { 2 - 3 } & 3 & $\begin{array}{l}\text { Lengua y Literatura, 30 ESO. Proyecto La casa del saber. Madrid, } \\
\text { Santillana (2007) }\end{array}$ \\
\cline { 2 - 3 } & 4 & $\begin{array}{l}\text { Lengua y Literatura, 40 ESO. Proyecto La casa del saber. Madrid, } \\
\text { Santillana (2008) }\end{array}$ \\
\hline \multirow{4}{*}{$\begin{array}{l}\text { SM. ESO. Enlace- } \\
\text { Proyecto Secundaria. } \\
2007\end{array}$} & 5 & $\begin{array}{l}\text { Lengua castellana y Literatura, 10 ESO. Enlace-Proyecto } \\
\text { Secundaria. Madrid, SM (2007) }\end{array}$ \\
\cline { 2 - 3 } & 6 & $\begin{array}{l}\text { Lengua castellana y Literatura, 20 ESO. Enlace-Proyecto } \\
\text { Secundaria. Madrid, SM (2008) }\end{array}$ \\
\cline { 2 - 3 } & 7 & $\begin{array}{l}\text { Lengua castellana y Literatura, 30 ESO. Enlace-Proyecto } \\
\text { Secundaria. Madrid, SM (2007) }\end{array}$ \\
\cline { 2 - 3 } & 8 & $\begin{array}{l}\text { Lengua castellana y Literatura, 40 ESO. Enlace-Proyecto } \\
\text { Secundaria. Madrid, SM (2008) }\end{array}$ \\
\hline
\end{tabular}

